\title{
Healthcare Workers' Willingness to Receive Influenza Vaccination in the Context of the COVID-19 Pandemic: A Survey in Southern Italy
}

\author{
Gabriella Di Giuseppe ${ }^{1}$, , Concetta P. Pelullo ${ }^{1}$ (D), Andrea Paolantonio ${ }^{1}$, Giorgia Della Polla ${ }^{2}$ \\ and Maria Pavia ${ }^{1, * \mathbb{D}}$ \\ 1 Department of Experimental Medicine, University of Campania “Luigi Vanvitelli", Via Armanni, 5, \\ 80138 Naples, Italy; gabriella.digiuseppe@unicampania.it (G.D.G.); \\ concettapaola.pelullo@unicampania.it (C.P.P.); andrea.paolantonio@studenti.unicampania.it (A.P.) \\ 2 Health Direction, Teaching Hospital of the University of Campania "Luigi Vanvitelli", Via S. Maria di \\ Costantinopoli 104, 80138 Naples, Italy; giorgia.dellapolla@unicampania.it \\ * Correspondence: maria.pavia@unicampania.it; Tel.: +39-0815667716
}

check for updates

Citation: Di Giuseppe, G.; Pelullo, C.P.; Paolantonio, A.; Della Polla, G.; Pavia, M. Healthcare Workers' Willingness to Receive Influenza Vaccination in the Context of the COVID-19 Pandemic: A Survey in Southern Italy. Vaccines 2021, 9, 766. https://doi.org/10.3390/

vaccines 9070766

Academic Editor: Ralph A. Tripp

Received: 21 April 2021

Accepted: 6 July 2021

Published: 9 July 2021

Publisher's Note: MDPI stays neutral with regard to jurisdictional claims in published maps and institutional affiliations.

Copyright: (C) 2021 by the authors. Licensee MDPI, Basel, Switzerland. This article is an open access article distributed under the terms and conditions of the Creative Commons Attribution (CC BY) license (https:// creativecommons.org/licenses/by/ $4.0 /)$.

\begin{abstract}
This cross-sectional survey was designed to evaluate hospital healthcare workers' (HCWs) willingness to receive the influenza vaccination during the COVID-19 pandemic and to identify the related determinants, since it is plausible that the two epidemics will coexist in future winters. Overall, $68 \%$ out of 490 participants expressed their willingness to receive influenza vaccination in the $2020 / 21$ season, with $95 \%$ of those ever and $45.8 \%$ of those never vaccinated in the previous six influenza seasons. Belief that influenza vaccine is useful in distinguishing influenza symptoms from those of COVID-19 and that the influenza vaccine is useful to prevent influenza in hospital settings, willingness to receive COVID-19 vaccination, having no concern about influenza vaccine side effects, concern about the possibility to transmit influenza to hospitalized patients, and influenza vaccination in previous years were all predictors of willingness to receive influenza vaccination. In the context of the COVID-19 pandemic, a relevant increase in the willingness to undergo influenza vaccination was reported. Therefore, interventions focused primarily on enabling factors are needed to promote the adherence to influenza vaccination in future seasons among HCWs.
\end{abstract}

Keywords: COVID-19 pandemic; healthcare workers; influenza vaccination; Italy; survey; vaccination coverage

\section{Introduction}

Influenza is known to be a global public health priority [1], affecting about $5-10 \%$ of the world population each year, with an estimated number of deaths ranging from 250,000 to 500,000 worldwide [2].

The transmission of influenza within healthcare facilities is widely reported in the literature, and healthcare workers (HCWs) represent a priority group for seasonal influenza vaccination recommendations. Immunization against influenza not only reduces the risk of infection among HCWs and the potential consequent defection and disruption of healthcare services, but also improves patient safety, reducing morbidity and mortality among the most vulnerable subjects [3].

In Italy, influenza affects almost $9 \%$ of the Italian population every year and, in particular, during the last season, there were 2,400,000 cases. Data on influenza are provided through InfluNet, a surveillance system coordinated by the National Institute of Health (NIH). It is based on the participation of general practitioners and pediatricians who report the number of cases of influenza like illness (ILI) observed each week among their patients [4]. Moreover, every year the Ministry of Health issues a document containing information on influenza epidemiological and virological surveillance, and providing 
recommendations for the seasonal influenza vaccination campaign. In this document, the target groups for influenza vaccination, such as HCWs, are identified and thresholds for monitoring the success of the campaigns are defined [5]. Although influenza vaccination in HCWs is strongly recommended, adherence is still very poor [6-10]. Accurate information on determinants of "vaccine hesitancy" among HCWs is not available, although it has been reported that it is mainly related to vaccine safety, especially in the case of the influenza vaccine [11].

In the context of poor adherence to influenza vaccination among HCWs, the cocirculation of influenza and SARS-CoV-2 viruses in the autumn/winter season 2020/21 has represented a public health challenge. It has been reported that coinfections with SARSCoV-2 and influenza or other respiratory viruses might produce more severe diseases [12,13], and differential diagnosis between the two syndromes might be facilitated if HCWs were vaccinated against influenza.

Thus, understanding HCWs willingness to receive influenza vaccination also has relevant implications for discerning whether the pandemic may influence HCWs willingness and related behavior concerning influenza vaccination.

Therefore, this cross-sectional survey was designed to evaluate HCWs' willingness to receive influenza vaccination during the COVID-19 pandemic and to identify related determinants in Italy. This knowledge may inform interventions for the upcoming influenza seasons, since it is plausible that the two epidemics will coexist in the future winters.

\section{Materials and Methods}

\subsection{Study Design and Setting}

This cross-sectional study was carried out in December 2020 and took place in three randomly selected public general hospitals distributed across Southern Italy (Campania region). The study population of HCWs was randomly sampled from the selected hospitals. The sample size was calculated by using the single population proportion formula with the assumption that $20 \%[10,14]$ of HCWs would be willing to undergo influenza vaccination, a confidence level of $95 \%$, a margin of error at $5 \%$, and considering a response rate of $60 \%$ [15-17]. Therefore, the final "minimum" needed sample size was $410 \mathrm{HCWs}$. Ethical approval was obtained from the Ethics Committee of the Teaching Hospital of the University of Campania "Luigi Vanvitelli".

\subsection{Data Collection}

Before data collection, the hospital directors received an information letter explaining the objectives and the methodology of the study, in order to obtain their approval. After the approval was received, the questionnaires were distributed to the selected HCWs with a cover letter that explained the purpose of the study, that participation was voluntary, and that confidentiality would be granted. The anonymization of any personal identifiers was assured, and an informed consent form to be signed by those who accepted to participate was also included. Moreover, to ensure maximum recruitment of the HCWs and to manage non-responders, follow-up visits were scheduled twice a week to each hospital. There were no incentives offered to HCWs who accepted to participate in the survey.

\subsection{Survey Questionnaire}

The questionnaire was built ad hoc for this survey after an extensive review of the literature assessing attitudes and adherence to vaccinations among HCWs [10,18-21]. The structured questionnaire was self-administered and consenting participants were asked to answer questions on four themes: (1) socio-demographic and professional characteristics (gender, age, nationality, marital status, parenthood, year of degree, professional role, ward, years in practice, average working hours and, average number of patients followed per week); (2) attitudes about influenza and COVID-19, and related vaccination strategies (perception of the risk of the disease, of safety and effectiveness of preventive measures, etc.); (3) behaviors regarding influenza vaccination uptake in the preceding influenza 
seasons (years 2014/15-2019/20); (4) sources of information, their quality and the need for additional information on influenza vaccination. Beliefs about influenza and related vaccination were measured on a 3-point Likert-type scale with options for agree, uncertain, and disagree, which, for the purpose of analysis, have been dichotomized as 1 for "agree" and 0 for "uncertain" and "disagree", whereas questions regarding the perception of the risk of contracting influenza and COVID-19 in the workplace, of transmitting influenza to patients, and beliefs about the usefulness and the safety of the influenza and the COVID19 vaccine were measured on a 10-point Likert scale ranging from 1 (not worried) to 10 (extremely worried). Willingness to undergo influenza vaccination in the 2020/21 season and influenza vaccination uptake in the 2014/15-2019/20 seasons were investigated through response options including "yes" and "no". For influenza vaccination uptake the option "do not remember" was also available. Finally, a list of potential reasons for having undergone influenza vaccination or not during the previous seasons was proposed with "yes" or "no" options for response for one or more reasons. The study was preceded by a pilot test among $50 \mathrm{HCWs}$, to evaluate the readability, clarity and correct sequence of the items. After conducting the pilot study, the reliability of the questionnaire was evaluated through the Cronbach's alpha, which indicated a high internal consistency. Calculation of the content validity indicated the unanimous agreement with the content and clarity of the questions (Cronbach's alpha $=0.73$ ).

\subsection{Statistical Analysis}

Descriptive and inferential statistics were used for the analyses of the data. First, a descriptive analysis was conducted to explore the main characteristics of the sample; second, the univariate analysis was performed using the chi-squared test for the categorical variables and the Student's $t$-test for the continuous variables. Then, multivariate logistic models were constructed to identify factors associated with the following outcomes of interest: willingness to receive influenza vaccination (no = 0; yes $=1$ ) (Model 1); willingness to receive influenza vaccination among those who had not received vaccination influenza in the previous six years vs. all others (no =0; yes $=1$ ) (Model 2). The independent variables that were shown to be associated at the univariate analysis or that were judged to potentially have influence on the investigated outcomes were included in the appropriate model.

The following independent variables were included in all models: gender (male $=0$; female $=1$ ); professional role (physician $=1$, nurse $=2$, other $=3$ ); usefulness of influenza vaccine to distinguish influenza symptoms from those of COVID-19 (no = 0; yes = 1); willingness to receive COVID-19 vaccine (no = 0; yes $=1$ ); concern about influenza vaccine side effects (continuous); concern about the risk of transmitting influenza to hospitalized patients (continuous); belief that influenza vaccine is useful to prevent influenza in hospital settings (continuous). In Model 1, the independent variable having been vaccinated against influenza in the previous years (no $=0$; yes $=1$ ) was also included.

Odds ratios (ORs) and 95\% confidence intervals (CIs) were presented in the logistic regression models. All statistical tests were two-sided, and the level of statistical significance was set at 0.05. Analyses were performed with the Stata software, version 15 [22].

\section{Results}

Of the $700 \mathrm{HCWs}$ invited to participate, 490 agreed and returned the survey for an overall response rate of $70 \%$. Table 1 shows the main investigated characteristics of the participating HCWs. The mean age was 50.7 years $(\mathrm{SD}=10.5) ; 54.4 \%$ were females, $74.8 \%$ were married/cohabitant; $72.6 \%$ had children; slightly more than half (52\%) were nurses; $34.1 \%$ worked in medical wards; the mean time from degree was 25.8 years $(\mathrm{SD}=10.8)$; and the mean number of hours worked per week was $36.5(\mathrm{SD}=4.4)$. 
Table 1. Willingness to receive influenza vaccination during the $2020 / 21$ season according to several characteristics.

\begin{tabular}{|c|c|c|c|c|}
\hline \multirow{2}{*}{$\begin{array}{c}\text { Characteristics } \\
\text { Socio-demographic and professional characteristics }\end{array}$} & \multicolumn{2}{|c|}{ Total } & \multicolumn{2}{|c|}{ Willingness to Receive Influenza Vaccination } \\
\hline & $\mathbf{N}$ & $\%$ & $\mathbf{N}$ & $\%$ \\
\hline \multicolumn{5}{|l|}{ Gender } \\
\hline Male & 221 & 45.6 & 165 & 74.7 \\
\hline \multirow[t]{2}{*}{ Female } & 264 & 54.4 & 165 & 62.5 \\
\hline & & & \multicolumn{2}{|c|}{$\chi^{2}=8.18,1 \mathrm{df}, p=0.004$} \\
\hline \multirow[t]{2}{*}{ Age (years) } & \multicolumn{2}{|c|}{$50.7 \pm 10.5 *$} & \multicolumn{2}{|c|}{$50.9 \pm 11 *$} \\
\hline & & & \multicolumn{2}{|c|}{$t$ test $=-0.65, \mathrm{df}=431, p=0.52$} \\
\hline \multicolumn{5}{|l|}{ Marital status } \\
\hline Unmarried/widowed/separated/divorced & 123 & 25.2 & 81 & 65.8 \\
\hline Married/cohabitant & 365 & 74.8 & 252 & 69 \\
\hline & & & \multicolumn{2}{|c|}{$\chi^{2}=0.43,1 \mathrm{df}, p=0.511$} \\
\hline \multicolumn{5}{|l|}{ Professional role } \\
\hline Physicians & 134 & 27.4 & 113 & 84.3 \\
\hline Nurses & 255 & 52 & 157 & 61.6 \\
\hline Other (nursing assistants, technicians, etc.) & 101 & 20.6 & 63 & 62.4 \\
\hline & & & \multicolumn{2}{|c|}{$\chi^{2}=22.72,2 \mathrm{df}, p<0.001$} \\
\hline \multicolumn{5}{|l|}{ Current working area } \\
\hline Medical & 167 & 34.1 & 107 & 64.1 \\
\hline Surgical & 161 & 32.9 & 109 & 67.7 \\
\hline Critical care & 90 & 18.4 & 64 & 71.1 \\
\hline Laboratory and Diagnostic & 72 & 14.6 & 53 & 73.6 \\
\hline & & & \multicolumn{2}{|c|}{$\chi^{2}=2.63,3 \mathrm{df}, p=0.452$} \\
\hline
\end{tabular}

Attitudes towards influenza and COVID-19

Influenza is a serious disease

$\begin{array}{ccccc}\text { Uncertain/disagree } & 310 & 63.3 & 184 & 59.3 \\ \text { Agree } & 180 & 36.7 & 149 & 82.7 \\ & & & \chi^{2}=28.69,1 \mathrm{df}, p<0.001\end{array}$

Influenza is a preventable disease

\begin{tabular}{|c|c|c|c|c|}
\hline Uncertain/disagree & 165 & 33.7 & 89 & 53.9 \\
\hline Agree & 325 & 66.3 & 244 & 75.1 \\
\hline & & & \multicolumn{2}{|c|}{$\chi^{2}=22.45,1 \mathrm{df}, p<0.001$} \\
\hline \multicolumn{5}{|c|}{ HCWs can be a source of influenza infection for patients } \\
\hline Uncertain/disagree & 93 & 19 & 53 & 57 \\
\hline \multirow[t]{2}{*}{ Agree } & 197 & 81 & 280 & 70.5 \\
\hline & & & \multicolumn{2}{|c|}{$\chi^{2}=6.34,1 \mathrm{df}, p=0.012$} \\
\hline \multicolumn{5}{|c|}{ Positive attitude towards influenza vaccination in HCWs } \\
\hline Uncertain/disagree & 117 & 23.9 & 37 & 31.6 \\
\hline \multirow[t]{2}{*}{ Agree } & 373 & 76.1 & 296 & 79.4 \\
\hline & & & \multicolumn{2}{|c|}{$\chi^{2}=93.19,1 \mathrm{df}, p<0.001$} \\
\hline
\end{tabular}


Table 1. Cont.

\begin{tabular}{|c|c|c|c|c|}
\hline Characteristics & \multicolumn{2}{|c|}{ Total } & \multicolumn{2}{|c|}{ Willingness to Receive Influenza Vaccination } \\
\hline \multicolumn{5}{|l|}{ Positive attitude towards vaccinations } \\
\hline Uncertain/disagree & 108 & 22 & 42 & 38.9 \\
\hline Agree & 382 & 78 & 291 & 76.2 \\
\hline & & & \multicolumn{2}{|c|}{$\chi^{2}=53.76,1 \mathrm{df}, p<0.001$} \\
\hline \multicolumn{5}{|l|}{ HCWs have a higher risk of getting influenza } \\
\hline Uncertain/disagree & 151 & 30.8 & 76 & 50.3 \\
\hline \multirow[t]{2}{*}{ Agree } & 339 & 69.2 & 257 & 75.8 \\
\hline & & & \multicolumn{2}{|c|}{$\chi^{2}=31.15,1 \mathrm{df}, p<0.001$} \\
\hline \multicolumn{5}{|l|}{ Influenza vaccination should be mandatory for $\mathrm{HCWs}$} \\
\hline Uncertain/disagree & 326 & 66.5 & 194 & 59.5 \\
\hline \multirow[t]{2}{*}{ Agree } & 164 & 33.5 & 139 & 84.8 \\
\hline & & & \multicolumn{2}{|c|}{$x^{2}=31.94,1 \mathrm{df}, p<0.001$} \\
\hline \multicolumn{5}{|l|}{$\begin{array}{l}\text { The influenza vaccination is useful to distinguish influenza } \\
\text { symptoms from COVID-19 symptoms }\end{array}$} \\
\hline Uncertain/disagree & 232 & 47.4 & 123 & 53 \\
\hline \multirow[t]{2}{*}{ Agree } & 258 & 52.6 & 210 & 81.4 \\
\hline & & & \multicolumn{2}{|c|}{$\chi^{2}=45.18,1 \mathrm{df}, p<0.001$} \\
\hline \multicolumn{5}{|l|}{ Willingness to receive COVID-19 vaccination } \\
\hline No & 118 & 24.1 & 41 & 34.7 \\
\hline \multirow[t]{2}{*}{ Yes } & 372 & 75.9 & 292 & 78.5 \\
\hline & & & \multicolumn{2}{|c|}{$\chi^{2}=78.74,1 \mathrm{df}, p<0.001$} \\
\hline \multirow[t]{2}{*}{ Concerns } & Total & & \multicolumn{2}{|c|}{ Willingness to receive influenza vaccination } \\
\hline & & & No & Yes \\
\hline \multirow[t]{2}{*}{ Concern about contracting influenza in the workplace (1-10) } & \multicolumn{2}{|c|}{$6.09 \pm 2.62 *$} & $5.55 \pm 2.63 *$ & $6.35 \pm 2.57 *$ \\
\hline & & & \multicolumn{2}{|c|}{$t$ test $=-3.21, \mathrm{df}=488, p=0.001$} \\
\hline \multirow[t]{2}{*}{$\begin{array}{l}\text { Concern about the possibility to transmit influenza to } \\
\text { hospitalized patients }(1-10)\end{array}$} & \multicolumn{2}{|c|}{$5.9 \pm 2.58 *$} & $5.01 \pm 2.64 *$ & $6.32 \pm 2.45 *$ \\
\hline & & & \multicolumn{2}{|c|}{$t$ test $=-5.39, \mathrm{df}=485, p<0.001$} \\
\hline \multirow[t]{2}{*}{$\begin{array}{l}\text { Belief that influenza vaccine is useful to prevent influenza in } \\
\text { hospital settings (1-10) }\end{array}$} & \multicolumn{2}{|c|}{$7.31 \pm 2.32 *$} & $5.92 \pm 2.40 *$ & $7.96 \pm 1.97 *$ \\
\hline & & & \multicolumn{2}{|c|}{$t$ test $=-9.94, \mathrm{df}=487, p<0.001$} \\
\hline \multirow[t]{2}{*}{ Concern about influenza vaccine side effects (1-10) } & \multicolumn{2}{|c|}{$5.66 \pm 2.9 *$} & $6.64 \pm 2.35 *$ & $5.20 \pm 3.03 *$ \\
\hline & & & $t$ test $=5$. & $p<0.001$ \\
\hline Perceived risk of contracting COVID-19 (1-10) & 8.55 & 1.73 * & $8.39 \pm 1.81 *$ & $8.63 \pm 1.69 *$ \\
\hline & & & $t$ test $=-$ & $5, p=0.15$ \\
\hline $\begin{array}{l}\text { Perceived risk of transmitting COVID-19 to their families } \\
\qquad(1-10)\end{array}$ & 9.17 & $1.45^{*}$ & $9.05 \pm 1.51 *$ & $9.22 \pm 1.43 *$ \\
\hline & & & $t$ test $=-$ & $8, p=0.22$ \\
\hline
\end{tabular}


Table 1. Cont

\begin{tabular}{|c|c|c|c|c|}
\hline \multirow{2}{*}{$\begin{array}{c}\text { Characteristics } \\
\text { Behaviors }\end{array}$} & \multicolumn{2}{|c|}{ Total } & \multicolumn{2}{|c|}{ Willingness to Receive Influenza Vaccination } \\
\hline & $\mathbf{N}$ & $\%$ & $\mathbf{N}$ & $\%$ \\
\hline \multicolumn{5}{|c|}{$\begin{array}{l}\text { Influenza vaccination uptake in the previous influenza } \\
\text { season }(2019 / 2020)\end{array}$} \\
\hline No & 290 & 59.2 & 135 & 46.5 \\
\hline Yes & 200 & 40.8 & 198 & 99 \\
\hline & & & \multicolumn{2}{|c|}{$\chi^{2}=149.53,1 \mathrm{df}, p<0.001$} \\
\hline \multicolumn{5}{|l|}{ Sources of information } \\
\hline \multicolumn{5}{|c|}{ Sources of information about influenza vaccination } \\
\hline Scientific journals & 277 & 56.5 & 210 & 75.8 \\
\hline Others (mass media, Internet, etc.) & 213 & 43.5 & 123 & 57.8 \\
\hline & & & \multicolumn{2}{|c|}{$\chi^{2}=18.05,1 \mathrm{df}, p<0.001$} \\
\hline \multicolumn{5}{|c|}{$\begin{array}{l}\text { Perceived quality of the information received on influenza } \\
\text { vaccination }\end{array}$} \\
\hline Insufficient/low & 137 & 28 & 79 & 56.7 \\
\hline Good/very good/excellent & 352 & 72 & 253 & 71.9 \\
\hline & & & \multicolumn{2}{|c|}{$\chi^{2}=9.14,1 \mathrm{df}, p=0.003$} \\
\hline \multicolumn{5}{|c|}{ Need for more information on influenza vaccination } \\
\hline No & 220 & 46.1 & 142 & 64.5 \\
\hline Yes & 257 & 53.9 & 183 & 71.2 \\
\hline
\end{tabular}

${ }^{*}$ Mean \pm Standard Deviation. Number for each item may not add up to total number of study population due to missing values.

The vast majority (81\%) agreed that HCWs can be a source for influenza infection for patients; $69.2 \%$ considered HCWs to be at high risk of contracting influenza; $66.3 \%$ considered influenza preventable and only $36.7 \%$ considered it a serious disease. Overall, $78 \%$ and $76.1 \%$ declared themselves to be favorable to recommended vaccinations and in particular to influenza vaccination for HCWs, respectively, whereas only $33.5 \%$ were favorable to mandatory influenza vaccination for HCWs.

The uptake of influenza vaccine in the previous influenza seasons showed an increase in the temporal trend ranging from $17.3 \%$ in the $2014 / 15$ season to $40.8 \%$ in the $2019 / 20$ season, with $273(55.7 \%)$ and $75(15.3 \%)$ reporting to have never and always undergone influenza vaccinations in the 2014/15-2019/20 seasons, respectively. Willingness to receive influenza vaccination in the 2020/21 season was expressed by $333(68 \%)$ participants and by $95.8 \%$ of those who had ever and by $45.8 \%$ of those who had never undergone influenza vaccination in the previous six seasons. Among those who expressed willingness to receive it, the most commonly reported reasons were the reduction in risk of infection $(74.9 \%)$, the effectiveness $(55.1 \%)$ and safety $(53.3 \%)$ of the vaccine, and that they believed themselves at risk of contracting influenza $(49.2 \%)$, whereas among those who were not willing to undergo influenza vaccination, the main reasons were concerns about the usefulness of the vaccine $(38.6 \%)$, considering themselves not to be at risk of contracting influenza (34.3\%), fear of adverse events (25.7\%), and doubts about the effectiveness of the vaccine $(15 \%)$ (Table 2).

Almost all HCWs stated to have obtained information about influenza vaccination (96.1\%). The preferred sources of information were scientific journals (56.5\%), mass media $(41.4 \%)$, the Internet (25.3\%), and colleagues (20.4\%). Moreover, 53.9\% reported the need for additional information about influenza vaccination. 
Table 2. Influenza vaccination uptake in previous seasons (2014/15-2019/20) and reasons for willingness to uptake in the 2020/21 season (490 obs).

\begin{tabular}{|c|c|c|}
\hline Uptake of Influenza Vaccine & $\mathbf{N}$ & $\%$ \\
\hline Never (2014/15-2019/20) & 273 & 55.7 \\
\hline $2014 / 15$ & 85 & 17.3 \\
\hline $2015 / 16$ & 89 & 18.2 \\
\hline 2016/17 & 103 & 21 \\
\hline $2017 / 18$ & 132 & 26.9 \\
\hline 2018/19 & 152 & 31 \\
\hline $2019 / 20$ & 200 & 40.8 \\
\hline Always (2014/15-2019/20) & 75 & 15.3 \\
\hline Willingness to receive influenza vaccination in the present season $(2020 / 21)$ & 333 & 68 \\
\hline Willingness (2020/21) among those who had ever been vaccinated $(2014 / 15-2019 / 20)$ (217 obs) & 208 & 95.8 \\
\hline $\begin{array}{l}\text { Willingness }(2020 / 21) \text { among those who had never been vaccinated in the previous six season } \\
\qquad(2014 / 15-2019 / 20)(273 \text { obs })\end{array}$ & 125 & 45.8 \\
\hline \multicolumn{3}{|l|}{ Reasons for willing to uptake in the present season $(2020 / 21)^{\circ}$} \\
\hline Reduction of risk of infection & 245 & 74.9 \\
\hline Effectiveness of the vaccine & 179 & 55.1 \\
\hline Safety of the vaccine & 174 & 53.3 \\
\hline Believe themselves at risk of contracting influenza & 160 & 49.2 \\
\hline \multicolumn{3}{|l|}{ Reasons for not willing to uptake in the present season $(2020 / 21) *$} \\
\hline Concerns about the usefulness of the vaccine & 54 & 38.6 \\
\hline Considering themselves not to be at risk of contracting influenza & 48 & 34.3 \\
\hline Fear of adverse events of the vaccine & 36 & 25.7 \\
\hline Doubts on effectiveness of the vaccine & 21 & 15 \\
\hline
\end{tabular}

${ }^{\circ}$ Among those who were willing to receive influenza vaccination in the present season. * Among those who were not willing to receive influenza vaccination in the present season.

Table 1 reports also the results of the univariate analysis on willingness to receive influenza vaccination according to several characteristics. It shows that this willingness was significantly associated with being male (74.7\% vs. $62.5 \%)$; being physicians $(84.3 \%)$ compared to nurses $(61.6 \%)$ or other HCWs $(62.4 \%)$; considering influenza a serious $(82.7 \%$ vs. $59.3 \%$ ) and preventable disease (75.1\% vs. $53.9 \%)$; considering HCWs a source of influenza infection for patients (70.5\% vs. $57 \%)$; having a positive attitude towards influenza vaccination in HCWs $(79.4 \%$ vs. $31.6 \%)$; considering HCWs at higher risk of contracting influenza (75.8\% vs. $50.3 \%)$; being favorable to mandatory influenza vaccination in HCWs ( $84.8 \%$ vs. $59.5 \%$ ); considering influenza vaccination useful to distinguish influenza symptoms from COVID-19 symptoms (81.4\% vs. 53\%); willingness to receive COVID-19 vaccination $(78.5 \%$ vs. $34.7 \%)$; being concerned about contracting influenza in the workplace (6.35 \pm 2.57 vs. $5.55 \pm 2.63)$; being concerned about the possibility of transmitting influenza to hospitalized patients $(6.32 \pm 2.45$ vs. $5.01 \pm 2.6)$; believing that influenza vaccine is useful to prevent influenza in hospital settings (7.96 \pm 1.97 vs. $5.92 \pm 2.40)$; not being concerned about influenza vaccine side effects ( $5.20 \pm 3.03$ vs. $6.64 \pm 2.35$ ); having received influenza vaccination in the previous influenza season (99\% vs. $46.5 \%)$; having used scientific journals as source of information on influenza vaccination $(75.8 \% \mathrm{vs} .57 .8 \%)$; and perceiving the quality of information received on influenza vaccination as good/very good/excellent (71.9\% vs. 56.7\%) (Table 1 ).

Many of these predictors were confirmed in the multivariate analysis, specifically: considering the influenza vaccination a useful tool to differentiate symptoms of influenza from 
those of COVID-19 (OR $=2.01 ; 95 \% \mathrm{CI}=1.23-3.57)$; belief that influenza vaccine is useful to prevent influenza in hospital settings $(\mathrm{OR}=1.25 ; 95 \% \mathrm{CI}=1.1-1.42)$; willingness to receive COVID-19 vaccination $(\mathrm{OR}=3.41 ; 95 \% \mathrm{CI}=1.87-6.22)$; not being concerned about influenza vaccine side effects $(\mathrm{OR}=0.82 ; 95 \% \mathrm{CI}=0.73-0.91)$; being concerned about the risk of transmitting influenza to hospitalized patients $(\mathrm{OR}=1.15 ; 95 \% \mathrm{CI}=1.03-1.29)$; and having been vaccinated against influenza in the previous years $(\mathrm{OR}=2.78 ; 95 \% \mathrm{CI}=1.85-4.19)$ were all significantly associated with willingness to receive influenza vaccination (Model 1 in Table 3). Moreover, considering the influenza vaccination a useful tool to differentiate symptoms of influenza from those of COVID-19 (OR $=1.65 ; 95 \% \mathrm{CI}=1.03-2.63)$, being female $(\mathrm{OR}=1.61 ; 95 \% \mathrm{CI}=1.03-2.5)$, and not being concerned about influenza vaccine side effects $(\mathrm{OR}=0.87 ; 95 \% \mathrm{CI}=0.8-0.95)$ were all significantly associated with willingness to receive influenza vaccination among those who had never undergone influenza vaccination in the preceding six influenza seasons, and willingness to receive the COVID-19 vaccination almost resembled association $(p=0.094)$ (Model 2 in Table 3 ).

Table 3. Multiple logistic regression analysis about willingness to receive the influenza vaccination according to several explanatory variables.

\begin{tabular}{|c|c|c|c|}
\hline Variable & OR & $95 \% \mathrm{CI}$ & $p$ \\
\hline \multicolumn{4}{|c|}{ Model 1. Willingness to receive influenza vaccination } \\
\hline \multicolumn{4}{|c|}{ Log likelihood $=-179.88, \chi^{2}=244.91(9 \mathrm{df}), p<0.0001$, No. of obs $=481$} \\
\hline Willingness to receive COVID-19 vaccination & 3.41 & $1.87-6.22$ & $<0.001$ \\
\hline No & $1.00 *$ & & \\
\hline Yes & 3.41 & $1.87-6.22$ & $<0.001$ \\
\hline \multicolumn{4}{|c|}{ Influenza vaccination uptake in the previous influenza seasons } \\
\hline No & $1.00 *$ & & \\
\hline Yes & 2.78 & $1.85-4.19$ & $<0.001$ \\
\hline \multicolumn{4}{|c|}{$\begin{array}{l}\text { Believing that influenza vaccination is useful to distinguish influenza symptoms from } \\
\qquad \text { COVID-19 symptoms }\end{array}$} \\
\hline No & $1.00 *$ & & \\
\hline Yes & 2.01 & $1.23-3.57$ & $<0.001$ \\
\hline \multicolumn{4}{|c|}{ Believing that influenza vaccine is useful to prevent influenza in hospital settings } \\
\hline No & $1.00 *$ & & \\
\hline Yes & 1.25 & $1.1-1.42$ & 0.001 \\
\hline \multicolumn{4}{|c|}{ Concern about the possibility to transmit influenza to hospitalized patients } \\
\hline No & $1.00 *$ & & \\
\hline Yes & 1.15 & $1.03-1.29$ & 0.011 \\
\hline \multicolumn{4}{|l|}{ Concern about influenza vaccine side effects } \\
\hline No & $1.00 *$ & & \\
\hline Yes & 0.82 & $0.73-0.91$ & $<0.001$ \\
\hline \multicolumn{4}{|l|}{ Gender } \\
\hline Males & $1.00 *$ & & \\
\hline Females & 0.99 & $0.58-1.67$ & 0.959 \\
\hline \multicolumn{4}{|l|}{ Professional role } \\
\hline Physicians & $1.00 *$ & & \\
\hline Nurses & 0.77 & $0.38-1.58$ & 0.482 \\
\hline Others (nursing assistants, technicians, etc.) & 0.97 & $0.42-2.22$ & 0.937 \\
\hline
\end{tabular}


Table 3. Cont.

\begin{tabular}{|c|c|c|c|}
\hline Variable & OR & $95 \% \mathrm{CI}$ & $p$ \\
\hline \multicolumn{4}{|c|}{$\begin{array}{l}\text { Model 2. Willingness to receive influenza vaccination among those who had not received influenza vaccination in the previous si } \\
\text { years vs. all others }\end{array}$} \\
\hline \multicolumn{4}{|c|}{ Log likelihood $=-259.4, \chi^{2}=30.2(8 \mathrm{df}), p<0.0001$, No. of obs $=481$} \\
\hline \multicolumn{4}{|c|}{$\begin{array}{l}\text { Believing that influenza vaccination is useful to distinguish influenza symptoms from } \\
\text { COVID-19 symptoms }\end{array}$} \\
\hline No & $1.00 *$ & & \\
\hline Yes & 1.65 & $1.03-2.63$ & 0.035 \\
\hline \multicolumn{4}{|l|}{ Willingness to receive COVID-19 vaccination } \\
\hline No & 1.00 * & & \\
\hline Yes & 1.65 & $0.92-2.95$ & 0.094 \\
\hline \multicolumn{4}{|l|}{ Gender } \\
\hline Males & $1.00 *$ & & \\
\hline Females & 1.61 & $1.03-2.5$ & 0.036 \\
\hline \multicolumn{4}{|l|}{ Concern about influenza vaccine side effects } \\
\hline No & $1.00 *$ & & \\
\hline Yes & 0.87 & $0.8-0.95$ & $<0.001$ \\
\hline \multicolumn{4}{|l|}{ Professional role } \\
\hline Physicians & $1.00 *$ & & \\
\hline Nurses & 1.43 & $0.83-2.47$ & 0.194 \\
\hline Other (nursing assistants, technicians, etc.) & 1.64 & $0.84-3.16$ & 0.140 \\
\hline \multicolumn{4}{|c|}{ Believing that influenza vaccine is useful to prevent influenza in hospital settings } \\
\hline No & $1.00 *$ & & \\
\hline Yes & 1.04 & $0.93-1.16$ & 0.426 \\
\hline \multicolumn{4}{|c|}{ Concern about the possibility to transmit influenza to hospitalized patients } \\
\hline No & $1.00 *$ & & \\
\hline Yes & 1.01 & $0.92-1.11$ & 0.780 \\
\hline
\end{tabular}

\section{Discussion}

Within the large body of literature exploring the propensity of HCWs to receive seasonal influenza vaccination, this study has investigated this willingness in the context of the ongoing COVID-19 pandemic, exploring the intention to uptake seasonal influenza vaccination and the related determinants, as well as the determinants of change in the willingness to be vaccinated in those who had not undergone this vaccination in the preceding six influenza seasons. In particular, the hypothesis of the study was that HCWs would be more willing to undergo influenza vaccination to diminish their own risk and that of their patients of coinfection with COVID-19 and to reduce the problems related to differential diagnosis between the two diseases. The findings of the study may be of interest to suggest the most appropriate interventions aimed at increasing seasonal influenza vaccination coverage in this strategic population group, by the identification of cues of action for the future influenza vaccination strategies, considering that it is plausible that the two epidemics will continue to coexist, at least in the near future.

The overall willingness to receive influenza vaccination reported by the participants was $68 \%$, a value that is within those reported in the systematic review by Bish and colleagues (22\% to $83 \%$ ) [23], and slightly higher compared to the mean adherence to influenza vaccination, which is generally less than $30 \%$ in HCWs, as reported by Dini and 
colleagues [7]. In the context of the COVID-19 pandemic, however, it is more interesting to investigate whether there has been a change in the intention to uptake the influenza vaccination compared to adherence in previous years. Indeed, consistently with the literature on this topic, one of the strongest predictors of this willingness was adherence to influenza vaccination in the previous seasons. It is of note that $95 \%$ of those who had undergone influenza vaccination in the previous seasons reported also being willing to undergo it in the present one. However, the most remarkable result is that almost half of those who reported themselves to have never had an influenza vaccination in the preceding six influenza seasons, were now willing to receive it. Since the proportion of HCWs who reported that they had never undergone this vaccination in the six preceding seasons was high (55.7\%), this finding is stimulating and worthy of a detailed analysis. It should be noted that data have shown an increasing trend in the uptake of influenza vaccination in the preceding six seasons, ranging from $17.3 \%$ in the $2014 / 15$ season to $40.8 \%$ in the $2019 / 20$ season, suggesting that strategies to develop higher adherence to this vaccination in HCWs have become increasingly successful, although the uptake rates are still unsatisfactory in this target group. Therefore, this additional increase in the willingness may be partly the consequence of this favoring temporal trend; however, it is plausible that the context of the COVID-19 pandemic might have been responsible, at least in part, for this increased willingness. These conclusions have been drawn by other studies that have investigated the role of the COVID-19 pandemic in influenza vaccination from different perspectives. In a survey conducted on HCWs in the UK, $44 \%$ of the participants reported they were more likely to have an influenza vaccine in the 2020/21 season due to the COVID-19 pandemic [24], whereas in an Italian teaching hospital the increase in influenza vaccination uptake among HCWs increased from $24.19 \%$ in the $2019 / 20$ season to $54.56 \%$ in the $2020 / 21$ season, although a rise to $30.35 \%$ was predicted by a model based on data from four previous campaigns [25]. Moreover, the results of a web-based survey performed in university students showed that $77.5 \%$ of them were willing to receive the flu vaccine, and among the predictive factors to undertake flu vaccination, there was a high level of concern and perceived vulnerability to the COVID-19 pandemic [26]. Therefore, the awareness of the relevance of influenza vaccination in the context of SARS-CoV-2 circulation is widespread in several settings and populations, stimulating the implementation of strategies to improve influenza vaccination coverage rates.

Further suggestions on the most appropriate measures to put in place to promote HCWs influenza vaccination in the upcoming seasons may be drawn by the examination of the factors that predicted willingness to receive it. We have already mentioned the role of adherence to influenza vaccination in the previous seasons, which has been repeatedly reported in studies investigating predictors of willingness and adherence to influenza vaccination [21,27-29], demonstrating that the experience of vaccination is satisfactory for HCWs, and represents an incentive for future vaccinations. Since in Italy influenza vaccination is recommended, but not mandatory in HCWs, the positive role of adherence to previous influenza vaccination campaigns pertains to those who voluntarily underwent vaccination. Indeed, in this study, although $76.1 \%$ expressed to be favorable to influenza vaccination in HCWs, only one third would favor mandatory influenza vaccination. Although mandatory vaccination for children is a consolidated but always controversial strategy [30,31], the debate on the opportunity for mandatory influenza vaccinations in HCWs is also long-standing [32], and has been relaunched during the COVID-19 pandemic [33]. The negative attitude towards mandatory influenza vaccination expressed by the majority of the surveyed HCWs is higher than that which resulted from a recent meta-analysis investigating this issue, reporting a pooled estimate of $61 \%$ of HCWs that were in favor of this policy [33]. In the same meta-analysis, however, a great heterogeneity among studies was revealed, with the lowest acceptance of mandatory policies expressed by European HCWs [33].

Confidence in the usefulness and the safety of a vaccine are consolidated predictors of willingness and adherence to vaccinations, and this was also the case for the surveyed 
HCWs, since considering influenza vaccination as a useful and safe prevention tool in the hospital settings was positively associated with willingness to receive the vaccine. Moreover, concern about the risk of transmitting influenza to hospitalized patients may be interpreted as an indicator of HCWs' awareness of their critical role in the protection of vulnerable subjects. All of these determinants have already been reported in the literature as determinants of a positive attitude of HCWs towards receiving influenza vaccination $[7,34-36]$, whereas it is noteworthy that in this last season willingness was also influenced by the COVID-19 pandemic. This is suggested by the findings that considering the influenza vaccination a useful tool to differentiate symptoms of influenza from those of COVID-19 and willingness to receive COVID-19 vaccination were significantly associated with intention to receive influenza vaccination. This has been confirmed by the results of the model that investigated the determinants of the positive change in the willingness to take up influenza vaccination in those who had not undergone it in the previous six years that showed that only the variables related to the COVID-19 pandemic and not being concerned about influenza vaccine side effects were associated with this change, with females being significantly more willing.

All taken together, these findings indicate that this changed positive attitude towards influenza vaccination is related to increased trust in the effectiveness and safety of the vaccine, an increased sense of responsibility towards patients and awareness of the crucial role of influenza vaccination in the context of the COVID-19 pandemic to reduce the burden of the disease and the pressure on healthcare systems, to facilitate differential diagnosis among overlapping clinical symptoms, and to decrease the probability of severe disease as the result of coinfection with influenza and SARS-CoV-2 viruses. Therefore, according to the results of this study, there seems to be no need for educational and promotional campaigns oriented to attitudinal barriers, and also mandatory policies do not appear to represent an appropriate strategy in this context. Interventions aimed at increasing HCWs' adherence to influenza vaccination in future seasons should probably be focused on enabling factors, such as those favoring access to and availability of vaccines. Indeed, it should also be acknowledged that campaigns involving education or promotion alone have sometimes resulted in minimal changes in vaccination rates [37-40], whereas a recent study has demonstrated the extraordinary role of enabling factors, such as the availability of worksite vaccination-dedicated clinics, in the promotion of $\mathrm{HCWs}^{\prime}$ adherence to recommended vaccinations [41].

\section{Limitations}

We are aware that the study has some potential limitations that should be underlined and considered when interpreting the results. First, as with most similar research on this topic, our survey was performed as cross-sectional, and it is well known that the crosssectional design does not allow any cause-effect relationship and poses many problems in relation to hypothesis testing since data on risk factors and outcomes are assessed at the same time. However, it was not our aim to draw conclusions on predictive relationships, but only to have insight on associations between several characteristics of HCWs and their willingness to receive influenza vaccination in the context of the COVID-19 pandemic. Therefore, the study design and setting were suitable to achieve the objectives of the study. Second, self-reported behaviors can result in the overestimation of "desirable" responses, with participants possibly having inflated compliance with recommendations of the influenza vaccination. Moreover, the information about their vaccination status was also self-reported and not based on vaccination records. This might be prone to recall, declaration, or desirability biases; therefore, an over or underestimation of coverage could have occurred. However, as the survey was self-administered and anonymous, and staff had voluntarily participated in the study, we believe that the responses were likely to be accurate with minimal social desirability bias. Previous published studies have reported a strong agreement between self-reported influenza vaccination status and the uptake documented in medical records. Therefore, this limitation is unlikely and may 
be weighted as minimal [42-44]. Finally, our study was conducted in a defined area of Southern Italy and might not be generalizable to other regions of the country. Despite these potential limitations, the extensive response to the questionnaire reduces the risk of the non-representativeness of the sample compared to the entire population.

\section{Conclusions}

The present study showed, in the context of the COVID-19 pandemic, a relevant increase in the willingness to undergo influenza vaccination, with almost all HCWs who had undergone influenza vaccination, and almost half of those who reported themselves to have never undergone influenza vaccination in previous influenza seasons, being willing to undergo it in the present season. In light of this positive attitude, interventions aimed at increasing HCWs' adherence to influenza vaccination in future seasons should probably be focused primarily on enabling factors, such as those favoring accesses to and availability of vaccines.

Author Contributions: Conceptualization, G.D.G., M.P.; methodology, G.D.G., M.P.; data acquisition: A.P.; formal analysis, G.D.G., C.P.P., G.D.P. and M.P.; resources, G.D.G., C.P.P., A.P., G.D.P., M.P.; data curation, G.D.G. and C.P.P.; writing—original draft preparation, G.D.G., C.P.P., M.P.; writing—review and editing, M.P.; supervision, M.P. All authors have read and agreed to the published version of the manuscript.

Funding: This research received no external funding.

Institutional Review Board Statement: The study was conducted according to the guidelines of the Declaration of Helsinki. Ethical review and approval were waived for this study, according to Linee guida per la classificazione e conduzione degli studi osservazionali sui farmaci, Determinazione Agenzia Italiana del Farmaco del 203 2008, Gazzetta Ufficiale n. 76 del 3132008.

Informed Consent Statement: Informed consent was obtained from all subjects involved in the study.

Data Availability Statement: The data presented in this study are available on request from the corresponding author.

Acknowledgments: The authors wish to express their gratitude to those who participated in this study and were willing to share their information. The members of the Collaborative Working Group are: Ferdinando Russo (Local Health Unit Caserta, Italy), Laura Leoncini, Federica Fucci (Hospital "Anastasia Guerriero", Marcianise, Italy), Diego Colaccio, Roberto Mansueto (Hospital "Ave Gratia Plena", Piedimonte Matese, Italy), Salvatore Moretta (Hospital "S. Rocco", Sessa Aurunca, Italy).

Conflicts of Interest: The authors declare no conflict of interest.

\section{References}

1. World Health Organization. Global Influenza Strategy 2019-2030. 2019. License: CC BY-NC-SA 3.0 IGO. Available online: https:/ / apps.who.int/iris/handle/10665/311184 (accessed on 20 April 2021).

2. Paget, J.; Spreeuwenberg, P.; Charu, V.; Taylor, R.J.; Iuliano, A.D.; Bresee, J.; Simonsen, L.; Viboud, C. Global Seasonal Influenzaassociated Mortality Collaborator Network and GLaMOR Collaborating Teams. Global mortality associated with seasonal influenza epidemics: New burden estimates and predictors from the GLaMOR Project. J. Glob. Health 2019, 9, 020421. [CrossRef]

3. Advisory Committee on Immunization Practices; Centers for Disease Control and Prevention (CDC). Immunization of health-care personnel: Tecommendations of the Advisory Committee on Immunization Practices (ACIP). MMWR Recomm. Rep. 2011, 60, $1-45$.

4. Italian Network for Surveillance of Influenza-InfluNet. Available online: https:/ /www.epicentro.iss.it/influenza/influnet (accessed on 15 June 2021).

5. Italian Ministry of Health. Circular 4 June 2020. Available online: https://www.trovanorme.salute.gov.it/norme/ renderNormsanPdf?anno $=2020 \&$ codLeg $=74451 \&$ parte $=1 \% 20 \&$ serie $=$ null (accessed on 15 June 2021).

6. Albano, L.; Matuozzo, A.; Marinelli, P.; Di Giuseppe, G. Knowledge, attitudes and behaviour of hospital health-care workers regarding influenza A/H1N1: A cross sectional survey. BMC Infect. Dis. 2014, 14, 208. [CrossRef]

7. Dini, G.; Toletone, A.; Sticchi, L.; Orsi, A.; Bragazzi, N.L.; Durando, P. Influenza vaccination in healthcare workers: A comprehensive critical appraisal of the literature. Hum. Vaccin. Immunother. 2018, 14, 772-789. [CrossRef] 
8. European Centre for Disease Prevention and Control. Seasonal Influenza Vaccination and Antiviral Use in EU/EEA Member StatesOverview of Vaccine Recommendations for 2017-2018 and Vaccination Coverage Rates for 2015-2016 and 2016-2017 Influenza Seasons; European Centre for Disease Prevention and Control: Stockholm, Sweden, 2018.

9. Napolitano, F.; Bianco, A.; D’Alessandro, A.; Papadopoli, R.; Angelillo, I.F. Healthcare workers' knowledge, beliefs, and coverage regarding vaccinations in critical care units in Italy. Vaccine 2019, 37, 6900-6906. [CrossRef]

10. Pelullo, C.P.; Della Polla, G.; Napolitano, F.; Di Giuseppe, G.; Angelillo, I.F. Healthcare workers' knowledge, attitudes, and practices about vaccinations: A cross-sectional study in Italy. Vaccines 2020, 8, 148. [CrossRef] [PubMed]

11. European Centre for Disease Prevention and Control. Vaccine Hesitancy among Healthcare Workers and Their Patients in Europe-A Qualitative Study; ECDC: Stockholm, Sweden, 2015; Available online: https://www.ecdc.europa.eu/sites/default/files/media/ en/publications/Publications/vaccine-hesitancy-among-healthcare-workers.pdf (accessed on 20 April 2021).

12. Stowe, J.; Tessier, E.; Zhao, H.; Guy, R.; Muller-Pebody, B.; Zambon, M.; Andrews, N.; Ramsay, M.; Lopez Bernal, J. Interactions between SARS-CoV-2 and influenza, and the impact of coinfection on disease severity: A test-negative design. Int. J. Epidemiol. 2021, dyab081. [CrossRef]

13. Yue, H.; Zhang, M.; Xing, L.; Wang, K.; Rao, X.; Liu, H.; Tian, J.; Zhou, P.; Deng, Y.; Shang, J. The epidemiology and clinical characteristics of co-infection of SARS-CoV-2 and influenza viruses in patients during COVID-19 outbreak. J. Med. Virol. 2020, 92, 2870-2873. [CrossRef] [PubMed]

14. Rong, H.; Lai, X.; Ma, X.; Hou, Z.; Li, S.; Jing, R.; Zhang, H.; Peng, Z.; Feng, L.; Fang, H. Seasonal influenza vaccination and recommendation: The difference between general practitioners and public health workers in China. Vaccines 2020, 8, 265. [CrossRef]

15. Burns, K.E.; Duffett, M.; Kho, M.E.; Meade, M.O.; Adhikari, N.K.; Sinuff, T.; Cook, D.J. A guide for the design and conduct of self-administered surveys of clinicians. CMAJ 2008, 179, 245-252. [CrossRef] [PubMed]

16. Hagemeister, M.H.; Stock, N.K.; Ludwig, T.; Heuschmann, P.; Vogel, U. Self-reported influenza vaccination rates and attitudes towards vaccination among health care workers: Results of a survey in a German university hospital. Public Health 2018, 154, 102-109. [CrossRef]

17. Di Giuseppe, G.; Pelullo, C.P.; Della Polla, G.; Pavia, M. Meningococcal disease and related vaccinations: Knowledge, attitudes, and practices among healthcare workers who provide care to patients with underlying high-risk medical conditions. Vaccines 2020, 8, 543. [CrossRef] [PubMed]

18. Sočan, M.; Erčulj, V.; Lajovic, J. Knowledge and attitudes on pandemic and seasonal influenza vaccination among Slovenian physicians and dentists. Eur. J. Public Health 2013, 23, 92-97. [CrossRef] [PubMed]

19. Durando, P.; Alicino, C.; Dini, G.; Barberis, I.; Bagnasco, A.M.; Iudici, R.; Zanini, M.; Martini, M.; Toletone, A.; Paganino, C.; et al. Determinants of adherence to seasonal influenza vaccination among healthcare workers from an Italian region: Results from a cross-sectional study. BMJ Open 2016, 6, e010779. [CrossRef] [PubMed]

20. Boey, L.; Bral, C.; Roelants, M.; De Schryver, A.; Godderis, L.; Hoppenbrouwers, K.; Vandermeulen, C. Attitudes, believes, determinants and organisational barriers behind the low seasonal influenza vaccination uptake in healthcare workers-A crosssectional survey. Vaccine 2018, 36, 3351-3358. [CrossRef]

21. Pichon, M.; Gaymard, A.; Zamolo, H.; Bazire, C.; Valette, M.; Sarkozy, F.; Lina, B. Web-based analysis of adherence to influenza vaccination among French healthcare workers. J. Clin. Virol. 2019, 116, 29-33. [CrossRef]

22. Stata Corporation. Stata Reference Manual Release 15.1; Stata Corporation: College Station, TX, USA, 2017.

23. Bish, A.; Yardley, L.; Nicoll, A.; Michie, S. Factors associated with uptake of vaccination against pandemic influenza: A systematic review. Vaccine 2011, 29, 6472-6484. [CrossRef]

24. Robbins, T.; Berry, L.; Wells, F.; Randeva, H.; Laird, S. Healthcare staff perceptions towards influenza and potential COVID-19 vaccination in the 2020 pandemic context. J. Hosp. Infect. 2021, 112, 45-48. [CrossRef]

25. Di Pumpo, M.; Vetrugno, G.; Pascucci, D.; Carini, E.; Beccia, V.; Sguera, A.; Zega, M.; Pani, M.; Cambieri, A.; Nurchis, M.C.; et al. Is COVID-19 a real incentive for flu vaccination? Let the numbers speak for themselves. Vaccines 2021, 9, 276. [CrossRef]

26. Pastorino, R.; Villani, L.; Mariani, M.; Ricciardi, W.; Graffigna, G.; Boccia, S. Impact of COVID-19 pandemic on flu and COVID-19 vaccination intentions among university students. Vaccines 2021, 9, 70. [CrossRef]

27. Della Polla, G.; Licata, F.; Angelillo, S.; Pelullo, C.P.; Bianco, A.; Angelillo, I.F. Characteristics of Healthcare Workers Vaccinated against Influenza in the Era of COVID-19. Vaccines 2021, 9, 695. [CrossRef] [PubMed]

28. Domnich, A.; Cambiaggi, M.; Vasco, A.; Maraniello, L.; Ansaldi, F.; Baldo, V.; Bonanni, P.; Calabrò, G.E.; Costantino, C.; de Waure, C.; et al. Attitudes and beliefs on influenza vaccination during the COVID-19 Pandemic: Results from a representative Italian survey. Vaccines 2020, 8, 711. [CrossRef] [PubMed]

29. Lim, D.W.; Ho, H.J.; Lee, L.T.; Chow, A.; Kyaw, W.M. Determinants of change in intention to receive influenza vaccination among health-care workers in Singapore. Hum. Vaccin. Immunother. 2020, 16, 1118-1124. [CrossRef]

30. Pelullo, C.P.; Marino, S.; Valdes, A.A.J.; Signoriello, G.; Attena, F. Is it reasonable to abandon obligatory vaccinations in Italy? A 2013 survey. Euro Surveill. 2014, 19, 20889.

31. Maltezou, H.C.; Ledda, C.; Rapisarda, V. Mandatory vaccinations for children in Italy: The need for a stable frame. Vaccine 2019, 37, 4419-4420. [CrossRef] [PubMed]

32. Maltezou, H.C.; Theodoridou, K.; Ledda, C.; Rapisarda, V.; Theodoridou, M. Vaccination of healthcare workers: Is mandatory vaccination needed? Expert Rev. Vaccines 2019, 18, 5-13. [CrossRef] [PubMed] 
33. Gualano, M.R.; Corradi, A.; Voglino, G.; Catozzi, D.; Olivero, E.; Corezzi, M.; Bert, F.; Siliquini, R. Healthcare workers' (HCWs) attitudes towards mandatory influenza vaccination: A systematic review and meta-analysis. Vaccine 2021, 39, 901-914. [CrossRef]

34. Vasilevska, M.; Ku, J.; Fisman, D.N. Factors associated with healthcare worker acceptance of vaccination: A systematic review and meta-analysis. Infect. Control Hosp. Epidemiol. 2014, 35, 699-708. [CrossRef]

35. Nowak, G.J.; Sheedy, K.; Bursey, K.; Smith, T.M.; Basket, M. Promoting influenza vaccination: Insights from a qualitative meta-analysis of 14 years of influenza-related communications research by U.S. Centers for Disease Control and Prevention (CDC). Vaccine 2015, 33, 2741-2756. [CrossRef]

36. Lehmann, B.A.; Chapman, G.B.; Franssen, F.M.E.; Kok, G.; Ruiter, R.A. Changing the default to promote influenza vaccination among health care workers. Vaccine 2016, 34, 1389-1392. [CrossRef]

37. Doratotaj, S.; Macknin, M.L.; Worley, S. A novel approach to improve influenza vaccination rates among health care professionals: A prospective randomized controlled trial. Am. J. Infect. Control 2008, 36, 301-303. [CrossRef] [PubMed]

38. Llupià, A.; García-Basteiro, A.L.; Olivé, V.; Costas, L.; Ríos, J.; Quesada, S.; Varela, P.; Bayas, J.M.; Trilla, A. New interventions to increase influenza vaccination rates in health care workers. Am. J. Infect. Control 2010, 38, 476-481. [CrossRef]

39. Riphagen-Dalhuisen, J.; Burgerhof, J.G.; Frijstein, G.; van der Geest-Blankert, A.D.; Danhof-Pont, M.B.; de Jager, H.J.; Bos, A.A.; Smeets, E.E.; de Vries, M.J.; Gallee, P.M.; et al. Hospital based cluster randomised controlled trial to assess effects of a multi-faceted programme on influenza vaccine coverage among 540 hospital healthcare workers and nosocomial influenza in the Netherlands, 2009 to 2011. Euro Surveill. 2013, 18, 20512. [CrossRef] [PubMed]

40. Van Den Akker, I.L.; Hulscher, M.E.; Verheij, T.J.M.; Riphagen-Dalhuisen, J.; van Delden, J.J.; Hak, E. How to develop a program to increase influenza vaccine uptake among workers in health care settings? Implement. Sci. 2011, 6, 47-55. [CrossRef]

41. De Sarro, C.; Papadopoli, R.; Cautela, V.; Nobile, C.G.A.; Pileggi, C.; Pavia, M. Vaccination coverage among health-care workers: Pre-post intervention study to assess impact of an on-site vaccination-dedicated clinic. Expert Rev. Vaccines 2021, 4, 1-7. [CrossRef]

42. Zimmerman, R.K.; Raymund, M.; Janosky, J.E.; Nowalk, M.P.; Fine, M.J. Sensitivity and specificity of patient self-report of influenza and pneumococcal polysaccharide vaccinations among elderly outpatients in diverse patient care strata. Vaccine 2003, 21, 1486-1491. [CrossRef]

43. Loulergue, P.; Moulin, F.; Vidal-Trecan, G.; Absi, Z.; Demontpion, C.; Menager, C.; Gorodetsky, M.; Gendrel, D.; Guillevin, L.; Launay, $\mathrm{O}$. Knowledge, attitudes and vaccination coverage of healthcare workers regarding occupational vaccinations. Vaccine 2009, 27, 4240-4243. [CrossRef] [PubMed]

44. Bouadma, L.; Barbier, F.; Biard, L.; Esposito-Farese, M.; Le Corre, B.; Macrez, A.; Salomon, L.; Bonnal, C.; Zanker, C.; Najem, C.; et al. Personal decision-making criteria related to seasonal and pandemic a(H1N1) influenza-vaccination acceptance among French healthcare workers. PLoS ONE 2012, 7, e38646. [CrossRef] 